\title{
Resistência ao tratamento no linfoma de Burkitt: Associação com mutações específicas no gene TP53?
}

\author{
Treatment resistance in Burkitt's lymphoma: Is it associated with specific mutations of the \\ TP53 gene?
}

Eliane P. S. Magluta ${ }^{1}$

Claudete E. Klumb ${ }^{2}$

\begin{abstract}
O linfoma de Burkitt (LB) surge a partir de uma célula do centro germinativo que perde o controle da proliferação devido à ativação do gene c-myc. A resistência à apoptose é uma causa importante da falha à quimioterapia na maioria dos cânceres e também no $L B$. A taxa alta de apoptose observada no LB em fases iniciais da gênese do tumor é seguida pelo desenvolvimento subseqüente de inativação de vias que levam à apoptose da célula. Uma importante via que se encontra alterada no LB é a via mediada pela proteína p53. Essa via é importante para o controle da proliferação celular em resposta ao dano no DNA. Dados da literatura mostram uma correlação entre mutações do gene TP53 com resistência ao tratamento. No entanto, alguns estudos têm demonstrado que diferentes tipos de mutações podem conferir respostas diferentes das células à quimioterapia. Isso tem sido observado em nossos estudos que mostram que linhagens celulares do LB com mutações diferentes da p53 apresentam uma resposta diferenciada à apoptose induzida por drogas que atuam por essa via, como, por exemplo, a doxorrubicina. Diferentes tipos de mutações conferem fenótipos funcionais distintos, embora nem sempre ocorra uma perda da função, o que pode ser um importante componente da resistência à quimioterapia no LB. Nesse artigo revisamos a literatura com relação à resposta ao tratamento no LB e discutimos o papel das mutações do gene TP53 na resistência à quimioterapia nesses tumores. Rev. bras. hematol. hemoter. 2008;30(1):41-46.
\end{abstract}

Palavras-chave: Linfoma de Burkitt; gene TP53; mutação; resistência; tratamento.

\section{Introdução}

Inicialmente descrito na África, o linfoma de Burkitt (LB) foi depois identificado em outras regiões. ${ }^{1} \mathrm{O}$ tumor tem origem numa célula derivada do centro germinativo (CG) que perde a regulação da proliferação em virtude da ativação do proto-oncogene $c$-myc ${ }^{2}$ e superexpressão da proteína C-MYC. A perda da regulação dessa proteína resulta na ativação e repressão de pelo menos nove genes regulados por ela, entre os quais ciclina D1, p27, o gene da enzima lactato- desidrogenase A, p19ARF, p53, Bax, Fas e Fas ligante entre outros. ${ }^{3,4,5}$

A classificação mais recente da Organização Mundial da Saúde (OMS) para as neoplasias linfóides identifica duas variantes morfológicas do LB: o LB clássico e o LB atípico ou Burkitt-like, uma variante cujo infiltrado tumoral apresenta diferenciação plasmocitóide, ou características intermediárias entre o linfoma difuso de grandes células e o LB. Esses tumores têm alta taxa de proliferação e expressam marcadores típicos de células do CG, como BCL-6 e CD10. ${ }^{6}$ Um padrão

${ }^{1}$ Aluna do Mestrado em Oncologia, Instituto Nacional do Câncer - Inca/Capes.

${ }^{2}$ Médica do Serviço de Hematologia do Hospital do Câncer - Inca; Doutora em Ciências, Biologia Molecular e Bioquímica, Instituto Oswaldo Cruz.

Laboratório de Hematologia Celular e Molecular - Serviço de Hematologia - HCI - Instituto Nacional do Câncer - Inca.

Correspondência: Claudete Esteves Klumb

Laboratório de Hematologia Celular e Molecular - Serviço de Hematologia, Hospital do Câncer I, Inca

Praça da Cruz Vermelha, $23 / 6^{\circ}$ andar - Centro

22230-130 - Rio de Janeiro-RJ - Brasil

Email: cklumb@inca.gov.br 


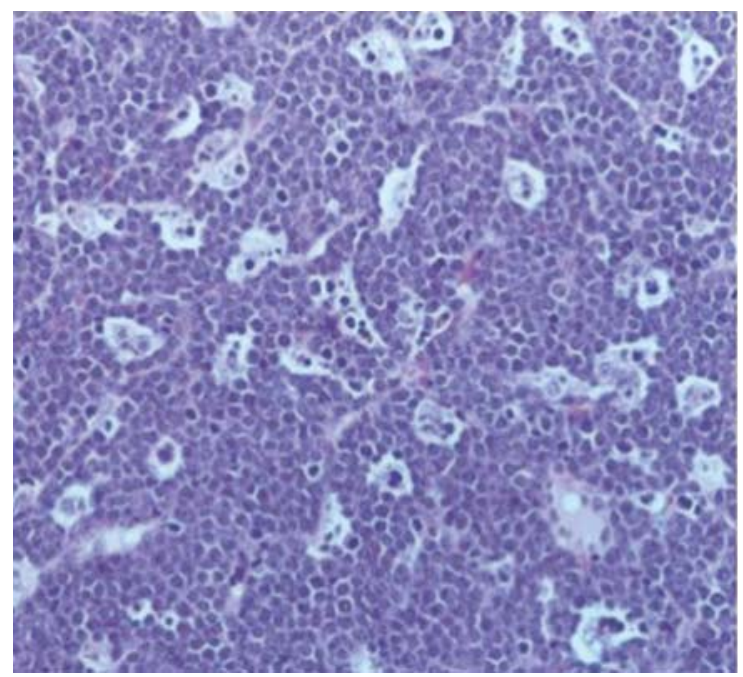

Figura 1. Padrão de céu estrelado característico do linfoma de Burkitt. Imagem original $\times 40$

clássico de céu estrelado é observado nesses tumores e se relaciona a uma alta taxa de apoptose (Figura 1).

Neste artigo revisamos a literatura com relação à resposta ao tratamento no LB e discutimos o papel das mutações do gene TP53 na resistência à quimioterapia. Com base em dados da literatura e em nossas observações, sugerimos que certos tipos de mutações podem ser o componente principal da resistência à quimioterapia nesses tumores.

\section{Fatores relacionados ao prognóstico e resposta à quimioterapia no LB}

A alta taxa de proliferação do LB (tempo de duplicação celular de 25 horas) favorece a entrada das células malignas no ciclo celular e a proliferação rápida entre os ciclos de quimioterapia, com posterior desenvolvimento de resistência. Regimes quimioterápicos intensivos e com intervalos de curta duração asseguram a manutenção da concentração sérica das drogas pelo menos por 48 a 72 horas e são a base atual do desenho dos protocolos de tratamento do LB resultando em alta eficácia. Os regimes quimioterápicos de curta duração foram inicialmente empregados em crianças com LB e incluíam agentes com reconhecida atividade no LB tais como ciclofosfamida, vincristina, metotrexate, doxorubicina e citarabina. Esses protocolos de tratamento resultaram em aumento da sobrevida livre de eventos (SLE) que atingiu taxas de $75 \%-89 \% .^{7-10}$ As estratégias fundamentais do sucesso desses protocolos foram o uso fracionado da ciclofosfamida, alternância de agentes citotóxicos sem resistência cruzada entre os ciclos do protocolo, redução da duração da terapia e profilaxia do sistema nervoso central. Diversos estudos têm demonstrado que o emprego de protocolos intensivos e de curta duração também resultou em aumento da taxa de SLE em pacientes adultos, à semelhança do que é observado em crianças; porém, os pacientes adultos apre- sentam um percentual mais baixo de remissão completa quando comparados aos pacientes pediátricos. ${ }^{11-13}$ Uma causa importante da falha à quimioterapia na maioria dos cânceres e também no LB é a resistência à apoptose. A taxa alta de apoptose observada no LB em fases iniciais da gênese do tumor é seguida pelo desenvolvimento subseqüente de inativação de vias que levam à apoptose da célula tumoral. ${ }^{14}$ Ainda é desconhecido se estes mecanismos que surgem ainda durante a gênese tumoral podem se manter ativos durante o tratamento, ou acrescidos de novas alterações que contribuem ou determinam a resistência desses tumores. Desta forma, a resistência adquirida a drogas empregadas no tratamento do câncer é ainda uma questão de elucidação complexa, também no contexto do tratamento do LB. A perda da regulação dos genes bcl-2 e TP53 são dois mecanismos relacionados à resistência à quimioterapia nos linfomas nãoHodgkin (LNH). ${ }^{4}$ Dentre os subtipos de LNH, o LB apresenta um percentual de mutações do gene TP53 de $20 \%$ a 30\%. ${ }^{15,16,17}$ Com relação ao LB, em um estudo publicado por nosso grupo observamos que algumas mutações da p53 estavam relacionadas à perda da função e associadas à ausência de resposta ao tratamento, ou recidiva da doença. ${ }^{17}$ Este estudo sugeriu que o tipo de mutação da proteína pode estar relacionado com a alteração da função normal da proteína. Este novo conceito na avaliação das mutações da p53 será discutido a seguir.

\section{Gene e proteína p53}

O gene supressor tumoral TP53 humano está localizado no braço curto do cromossomo 17 (região p13.1). Ele possui 20 kb de DNA e é composto por 11 éxons. Os éxons 2, 4, 5 , 7 e 8 codificam cinco regiões altamente conservadas durante a evolução (domínios I-V) apresentando homologia estrutural com diversas espécies. ${ }^{18}$ Essas regiões são conservadas pelo fato de que são responsáveis por funções cruciais da proteína p53.

A proteína de $53 \mathrm{kD}$ codificada por esse gene, a proteína p53, é um fator de transcrição que possui quatro domínios funcionais: (1) domínio de transativação localizado na região amino-terminal, que compreende os oitenta primeiros aminoácidos; (2) domínio de ligação ao DNA, localizado na porção central da proteína; (3) domínio de oligomerização e (4) domínio de tetramerização. Os dois últimos estão localizados na porção carboxi-terminal da proteína. ${ }^{19,20}$

A atividade da proteína p53 selvagem é fortemente estimulada por estresse genotóxico, como dano ao DNA, e leva à inibição do crescimento celular pelo bloqueio do ciclo celular, ou pela indução de apoptose (morte celular programada). ${ }^{21}$

Células normais apresentam níveis extremamente baixos de proteína p53, pelo fato da proteína ser rapidamente degradada após a síntese. A proteína p53 é ativada quando ocorre dano ao DNA, por sinais exógenos e endógenos, 
que incluem, por exemplo, radiação gama, ${ }^{22,23}$ radiação UV ${ }^{24,25}$ e substâncias químicas. ${ }^{26}$ A p53 ativada causa então a transativação do gene $p 21$-waf1 e ativação da proteína p21. Uma vez ativada, a p21 liga-se e inibe a atividade de complexos ciclina-CDK, bloqueando as células na fase G1 do ciclo celular ${ }^{27,28}$ e, desta forma, dando tempo para que ocorra o reparo do DNA. Caso o dano seja irreparável, a proteína p53 atua causando apoptose das células. ${ }^{29}$

\section{Mutações no gene TP53 e status funcional da proteína}

Mutação do gene TP53 é a lesão genética mais comum em muitas formas de neoplasias humanas herdadas e adquiridas. Essas mutações foram encontradas em cânceres de mama, cólon, bexiga, pâncreas e pulmão, assim como tumores do cérebro, leucemias, linfomas, carcinomas gástricos, hepatocarcinomas e osteosarcomas. As mutações da p53 geralmente são encontradas nas regiões conservadas da proteína, ${ }^{30}$ e cerca de $74 \%$ dessas mutações são missense (troca de um nucleotídeo). Essa fração de mutações missense é muito maior do que em outros genes supressores de tumor, e isso sugere que proteínas p53 mutadas conferem alguma vantagem seletiva na carcinogênese, talvez por uma função antiapoptótica. Formas mutantes da p53 têm a capacidade de interferir com a apoptose dependente de p53 e com a apoptose independente da p53, mecanismo este ainda desconhecido, mas que pode envolver transativação. ${ }^{31}$

Estudos que analisaram o significado de mutações pontuais do gene TP53 em relação ao tipo de tumor ${ }^{32,33}$ mostraram que mais de $90 \%$ dessas mutações estavam agrupadas na parte central da p53 e afetavam aminoácidos conservados em todas as espécies da proteína.

Muitos agentes físicos e químicos usados rotineiramente na terapia do câncer, cuja ação é a indução do dano ao DNA, são potentes ativadores da p53, embora a influência da p53 na sensibilidade da célula a estes agentes ainda seja controversa. Resultados conflitantes correlacionando o status da p53 à sensibilidade ou resistência aos quimioterápicos têm sido atribuídos a diferenças tecido-específicas na resposta aos quimioterápicos mediada pela p53. ${ }^{34}$ Em alguns sistemas, a inativação da p53 resulta em aumento da resistência, sugerindo que algumas vias que levam à morte celular são dependentes de p53. ${ }^{35}$ No entanto, em outros sistemas, a inativação de p53 selvagem tem sido correlacionada ao aumento da sensibilidade à radiação ionizante. ${ }^{36}$ Essa diferença na resistência pode ser causada pelo fato de que uma mutação do gene TP53 não leva necessariamente a uma perda de função da proteína. Alguns tipos de mutações, chamadas de mutantes de ganho de função, exercem efeitos que a proteína p53 selvagem não exerce, como, por exemplo, in vitro, proliferação aumentada, atividade antiapoptótica, resistência aumentada à quimioterapia e, in vivo, gênese e invasividade do tumor. ${ }^{37}$ A mudança de conforma- ção da proteína não é um pré-requisito absoluto para inativação e dessa forma não deve ser usada para estabelecer o status da proteína, como mostrado pelo fato de que várias mutantes inativas da p53 possuem conformação selvagem da proteína. ${ }^{38}$

O comportamento diferencial da p53 com relação à resistência a agentes quimioterápicos depende do tipo de mutação e do tipo e concentração do fármaco, como demonstrado em um estudo com uma linhagem celular transfectada com diferentes mutantes de p53, que apresentaram diferentes respostas que variaram com o tipo de mutação e o fármaco utilizado. Neste estudo, como exemplo, no caso do etoposídeo, as mutações His175 e His179, que alteram a conformação da proteína p53, foram mais potentes do que mutações Trp248 e His273, que não alteram a conformação da proteína, quebrando apenas ligações p53-DNA específicas. ${ }^{39}$

Em um estudo em curso, nosso grupo avaliou a resposta à quimioterapia em linhagens celulares do LB com mutações em diferentes códons do gene TP53. Por meio de um ensaio de viabilidade celular, observou-se que a linhagem Daudi, derivada de um paciente com LB (apresentando uma mutação nonsense no códon 213) foi mais resistente a fármacos como doxorrubicina, etoposídeo e cisplatina, quando comparada com outras linhagens do mesmo linfoma, com mutações missense nos códons 234 (Raji), 248 (Namalwa) e 254 (Ramos). Neste estudo, a concentração desses quimioterápicos necessária para inviabilizar 50\% das células da linhagem Daudi foi consideravelmente maior que nas outras linhagens, que apresentaram o mesmo percentual de inviabilidade celular com concentrações menores de fármaco, sugerindo que algumas mutações do gene TP53 no LB podem contribuir para uma função alterada da proteína, tendo como resultado uma resposta à indução de morte via p53 diferente (Figuras 2 e 3, resultados dos autores).

Como pode ser observado na Figura 2, uma diferente resposta ao quimioterápico doxorrubicina (Doxo) em 24 horas foi detectada na linhagem Daudi, que apresentou maior resistência, necessitando de uma concentração de 2,5 $\mathrm{MM}$ para inviabilizar aproximadamente $20 \%$ das células, enquanto as outras linhagens, com a mesma concentração, apresentavam mais de $35 \%$ de inviabilidade celular. Esse ensaio baseia-se na capacidade da enzima desidrogenase mitocondrial, em células viáveis, clivar os anéis tetrazolium do MTT [brometo de 3-(4,5-dimetiltiazol-2-il)-2,5-difeniltetrazolium)] formando cristais de formazana azul escuro, que são impermeáveis às membranas celulares, e, dessa forma, acumulam-se dentro das células viáveis. Com a solubilização desses cristais por um solvente, no caso dimetil sulfóxido (DMSO), pode-se quantificar o número de células viáveis por um simples ensaio colorimétrico. O número de células viáveis é diretamente proporcional à quantidade de cristais formados. ${ }^{40}$

Na Figura 3, a apoptose induzida pelo mesmo quimioterápico foi avaliada. Com a utilização de concentrações de 


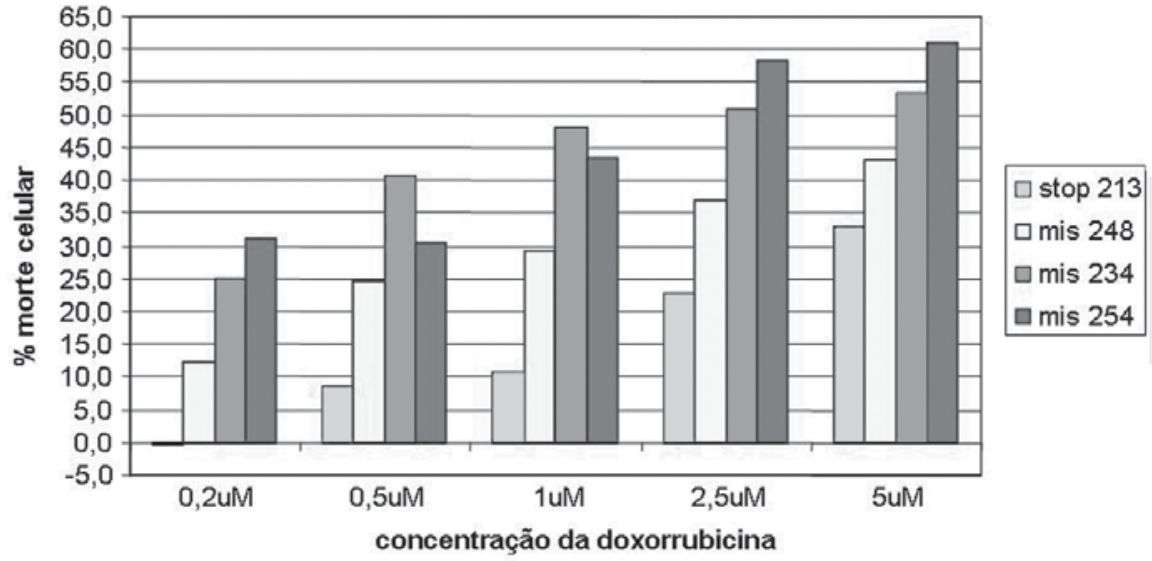

Figura 2. Percentual de viabilidade celular em 24 horas analisado através do método de MTT em linhagens celulares com diferentes mutações do gene TP53 expostas a diferentes concentrações do quimioterápico doxorrubicina. Em uma visualização gráfica observa-se que foi necessário uma concentração maior do fármaco para inviabilizar $20 \%$ das células da linhagem Daudi quando comparada as outras linhagens expostas as mesmas concentrações
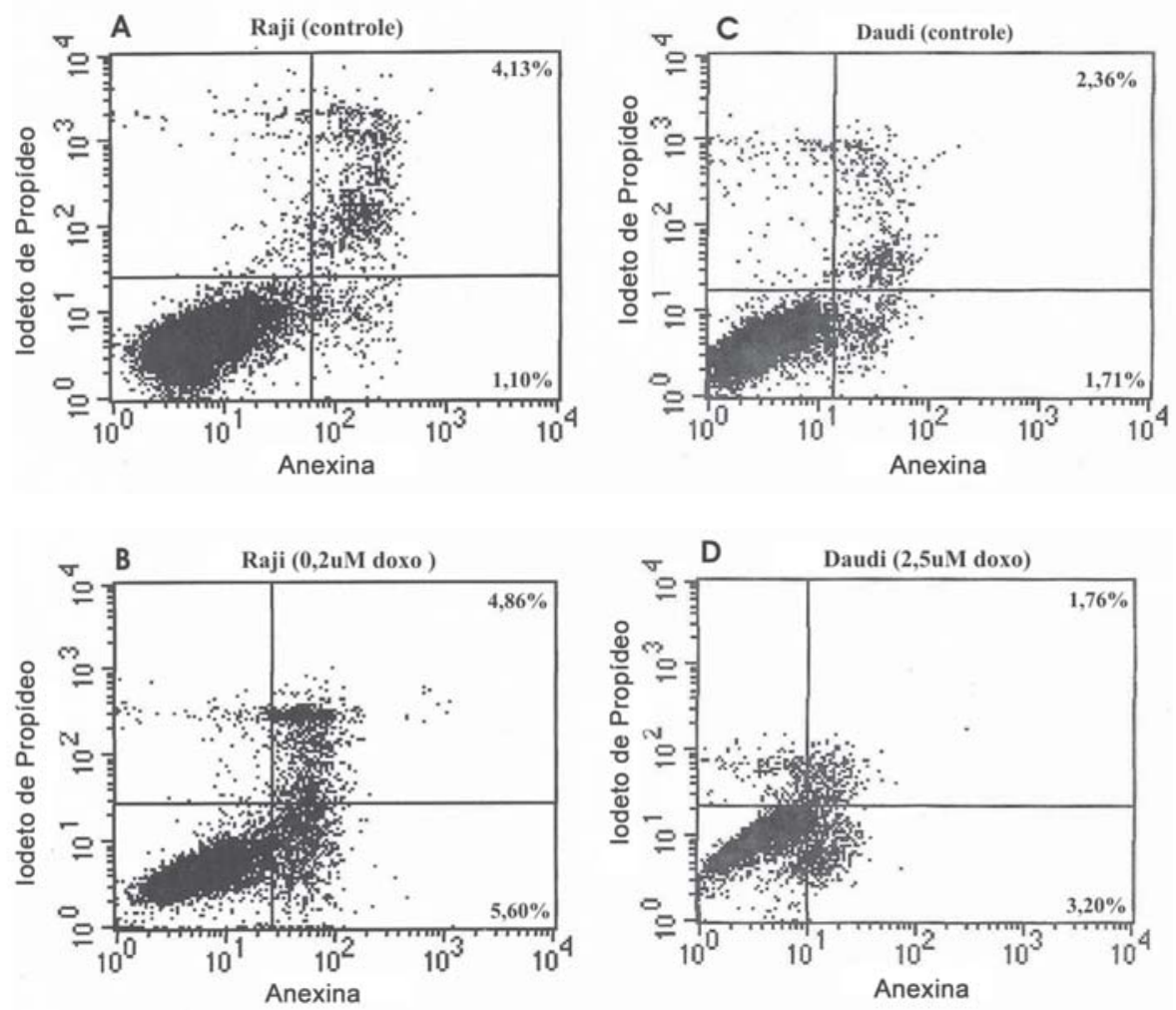

Figura 3. Análise de apoptose utilizando o ensaio de citometria de fluxo com Anexina $V$ que se liga a fosfatidilserina das células em apoptose determinando sua marcação. As células em necrose são identificadas pelo uso de iodeto de propídio. Nesse ensaio realizado com as linhagens Raji (mis234) e Daudi (stop213) com a utilização de doxorrubicina (doxo) e sem a droga (controle), o percentual de apoptose espontânea, controle, para essas linhagens foi de 5,23\% e 4,07\%, respectivamente (painéis A e C), e o percentual de apoptose induzida (descontado o percentual de apoptose da amostra controle) pela doxo na concentração de 0,2 $\mu \mathrm{M}$ para a linhagem Raji e 2,5 $\mu \mathrm{M}$ para Daudi, em 24 horas, foi de $5,23 \%$ e $0,89 \%$, (painéis B e D).
$0,2 \mu \mathrm{M}$ e $2,5 \mu \mathrm{M}$ de doxo (que mostraram no ensaio de viabilidade celular capacidade de inviabilizar cerca de $20 \%$ das células das linhagens Raji e Daudi respectivamente) observou-se uma porcentagem maior de apoptose induzida por doxo na linhagem Raji (5,23\%) quando comparada a Daudi (0,89\%) mesmo com uma concentração muito mais baixa de doxo, o que mostra uma maior resistência da linhagem Daudi a essa droga. Isso pode ser devido à natureza da mutação do gene TP53 nessas linhagens.

\section{Conclusões e direções futuras}

O LB é um tumor com alta taxa de resposta ao tratamento e é uma doença curável na maioria dos casos. Entretanto, no caso de recidiva ou refratariedade ao tratamento, nenhuma abordagem terapêutica é eficaz. ${ }^{41}$ A questão da resistência ao tratamento no LB ainda é um desafio e a compreensão dos mecanismos envolvidos é fundamental na busca de novas abordagens terapêuticas.

As linhagens celulares de LB analisadas em nosso estudo não apresentam perfil de resistência mediado por bombas de extrusão de drogas (Multidrug Resistance, MDR) como observado em um estudo prévio realizado por nosso grupo, que mostrou, através do ensaio de efluxo de rodamina, que as bombas de efluxo não são funcionais nessas linhagens (comunicação pessoal).

Em um percentual variando de $2 \%$ a $44 \%$ dos casos de linfomas não associados ao vírus HIV foi detectada a expressão do gene $m d r-1$ ao diagnóstico; entretanto, em alguns casos há um aumento da expressão de MDR-1 em pacientes que foram expostos à quimioterapia e, ainda, observou-se que essa expressão está associada com uma resposta diminuída à quimioterapia. ${ }^{42}$ Embora as proteínas MRP e PgP possam estar relacionadas à resistência ao tratamento 
nos linfomas, em geral esse mecanismo provavelmente não é responsável pela resistência ao tratamento no LB. Um potencial mecanismo de resistência no LB poderia estar relacionado ao status funcional da proteína p53.

Em nossos estudos, uma linhagem com uma mutação que resulta em uma proteína com um códon de parada apresentou-se mais resistente ao tratamento com quimioterápicos que induzem morte via p53, como doxorrubicina, etoposídeo e cisplatina, quando comparada a linhagens com outras mutações (missense), que provavelmente não alteram estruturalmente a proteína, permitindo que, embora mutada, ela ainda seja funcional. Martin et al. mostram que muitas mutações do gene TP53 não podem ser explicadas usando-se apenas critérios de avaliação estrutural, e que o efeito biológico de uma substituição não é necessariamente proporcional à extensão de perturbação estrutural prevista. Dessa forma, a análise das propriedades biológicas das mutações é importante para revelar as funções exatas dessas mutantes. ${ }^{43}$

Além da mutação da p53, outras vias de indução de apoptose podem estar comprometidas no LB. A resposta aos sinais de morte celular é modulada pelo balanço da expressão de proteínas pro e antiapoptóticas. A resistência à apoptose pode resultar da perda da função de proteínas próapoptóticas ou ganho de função de proteínas antiapoptóticas. Gutierrez et al. demonstraram que o gene Bax (próapoptótico), com freqüência apresenta-se mutado no LB resultando em resistência à apoptose. ${ }^{44} \mathrm{Um}$ estudo recente em linhagens celulares derivadas do LB mostrou alterações de outras proteínas relacionadas à apoptose como proteínas inibidoras da apoptose denominadas IAPs (inhibitors of apoptosis protein) e proteínas da família MAP-kinases também envolvidas em sinais que resultam em apoptose independente da via p53..$^{45}$

Neste artigo nós discutimos alguns conceitos importantes sobre o tratamento do LB e, com base em alguns resultados preliminares, propomos uma hipótese de como alterações do gene supressor tumoral TP53 poderiam atuar conferindo resistência ao tratamento no LB. No entanto, embora seja reconhecido que a via dependente de p53 está comprometida no LB, mais estudos são necessários para elucidar os mecanismos de desenvolvimento de resistência ao tratamento no LB. A alteração de outras vias relacionadas à apoptose em linhagens do LB sugere que, além da via mediada pela p53, outros mecanismos podem ser operantes. ${ }^{46}$ Esta informação aumenta o valor da utilização de linhagens do LB como ferramentas de identificação na seleção de novas moléculas e drogas indutoras de apoptose. ${ }^{45}$

\section{Abstract}

Burkitt's lymphoma (BL) originates from a germinative centre cell that loses proliferation control due to activation of the c-myc gene. Apoptosis resistance is a major cause of chemotherapy failure in most kinds of cancers, including BL. The high rate of apoptosis seen in the early steps of genesis of BL is followed by a subsequent development of inactivation of pathways leading to cell death by apoptosis. A major pathway known to be altered in $B L$ is the one mediated by the p53 protein. This pathway is important to control cell proliferation in response to DNA damage. Data from the literature show a correlation between TP53 gene mutations and treatment resistance. However, some studies have demonstrated that distinct types of mutations have the ability to confer different cell responses to chemotherapy. We found that BL cell lines bearing distinct mutations of p53 also present different responses to drug-induced apoptosis, when using drugs that act through this pathway, such as doxorubicin. Different types of mutations might confer distinct functional phenotypes. Loss of function does not always occur which may be considered an important component of chemotherapy resistance in $B L$. In this article we review publications regarding the response to treatment in BL while we discuss the role of TP53 gene mutations in chemotherapy resistance of these tumors. Rev. bras. hematol. hemoter. 2008;30(1):41-46.

Key words: Burkitt's lymphoma; TP53 gene; mutation; resistance; treatment.

\section{Agradecimentos}

Agradecemos à Dra Raquel C. Maia por suas valiosas sugestões e revisão do artigo e à Coordenação de Aperfeiçoamento de Pessoal do Ensino Superior (Capes).

\section{Referências Bibliográficas}

1. Burkitt D. A sarcoma involving the jaws in African children. Br J Surg. 1958;46:218-23.

2. Magrath I. The pathogenesis of Burkitt's lymphoma. Adv Cancer Res. 1990;55:133-270.

3. Hecht J, Aster J. Molecular biology of Burkitt's lymphoma. J Clin Oncol. 2000;18:3703-21.

4. Sanchez-Beato M, Sanchez-Aguilera A, Pires M. Cell cycle deregulation in B-cell lymphomas. Blood. 2003;101:1120-35.

5. Coller H, Grandori C, Tamayo P et al. Expression analysis with oligonucleotide microarrays revels the Myc regulates genes involved in growth, cell cycle signaling, and adhesion. Proc Natl Acad Sci USA. 2000;97:3260-5.

6. Harris N, Jaffe E, Diebold J et al. World Heath Organization Classification of Neoplastic Diseases of Lymphoid Tissues: Report of Clinical Advisory Committee Meeting-Arlie House, Virginia, November 1997. J Clin Oncol. 1999;17:3835-49.

7. Reiter A, Scharappe M, Tiemann $\mathrm{M}$ et al. Improved treatment results in childhood B-cell neoplasms with tailored intensification of therapy: A report of the Berlin-Frankfurt-Münster Group trial NHL-BFM 90. Blood. 1999;94:3294-306.

8. Patte C, Auperin A, Michon J et al. The Societé Française d' Pédiatric LMB89 protocol: highly effective multiagent chemotherapy tailored to tumor burden and initial response in 561 unselected children with B-cell lymphomas and L3 leukemia. Blood. 2001;97:3370-9.

9. Cairo MS, Sposto R, Perkins SL et al. Burkitt's and Burkitt-like lymphoma in children and adolescents: a review of children's Cancer Group experience. Br J Haematol. 2003;120:660-70. 
10. Klumb CE, Schramm MT, de Resende LM et al. Treatment of children with B-cell non-Hodgkin's lymphoma in developing countries: The experience of a single center in Brazil. J Pediatr Hematol Oncol. 2004;7:462-7.

11. Magrath I, Adde M, Shad A, et al. Adults and children with small non-cleaved-cell lymphoma have a similar excellent outcome when treated with the same chemotherapy regimen. J Clin Oncol. 1996; 14:925-34.

12. Hoelzer D, Ludwig W-D Thiel E et al. Improved outcome in adult B cell acute lymphoblastic leukemia. Blood. 1996;87:495-508.

13. Thomas D, Cortes J, O' Brian S et al. Hyper-CVAD program in Burkitt's type adult acute lymphoblastic leukemia. J Clin Oncol. 1999;17:2461-70.

14. Gaidano G, Ballerini P, Gong JZ et al. p53 mutations in human lymphoid malignancies: association with Burkitt lymphoma and chronic lymphocytic leukemia. Proc Natl Acad Sci USA. 1991; 88:5413-17.

15. Preudhomme C, Dervite I, Wattel E et al. Clinical significance of p53 mutations in newly diagnosed Burkitt's lymphoma and acute lymphoblastic leukemia: a report of 48 cases. J Clin Oncol. 1995; 13:812-20.

16. Ichikawa A, Kinoshita T, Watanabe $\mathrm{T}$ et al. Mutations of the p53 gene as a prognostic factor in aggressive B-cell lymphoma. N Engl J Med. 1997;337(8):529-34.

17. Klumb CE, Furtado DR, de Resende LM et al. DNA sequence profile of TP53 gene mutations in childhood B-cell non-Hodgkin's lymphomas: prognostic implications. Eur J Haematol. 2003; 71:81-90.

18. Benchimol S, Lamb P, Crawford LV et al. Transformation associated p53 protein is encoded by a gene on human chromosome 17 . Somat Cell Mol Genet. 1985;11(5):505-10.

19. Prokocimer M, Rotter V. Structure and function of p53 in normal cells and their aberrations in cancer cells: projection on the hematologic cell lineages. Blood. 1994;84(8):2391-2411.

20. Martin A. Lè gène suppresseur de tumeur p53 (1re partie) Structure, function et mécanismes d'inactivation. Ann Pathol. 1995;15(3): 178-83.

21. Bates S, Vousden KH. p53 in signaling checkpoint arrest or apoptosis. Curr Opin Genet Dev. 1996;6(1):12-18.

22. Aloni-Grinstein R, Schwartz D, Rotter V. Accumulation of wildtype p53 protein upon gamma-irradiation induces a G2 arrestdependent immunoglobulin kappa light chain gene expression. EMBO J. 1995;14(7):1392-401.

23. Kuerbitz SJ, Plunkett BS, Walsh WV et al. Wild-type p53 is a cell cycle checkpoint determinant following irradiation. Proc Natl Acad Sci USA. 1992;89(16):7491-5.

24. Maltzman W, Czyzyk L. UV irradiation stimulates levels of p53 cellular tumor antigen in nontransformed mouse cells. Mol Cell Biol. 1984;4(9):1689-94.

25. Lu X, Lane DP. Differential induction of transcriptionally active p53 following UV or ionizing radiation: defects in chromosome instability syndromes? Cell. 1993;75(4):765-78.

26. Zhan Q, Carrier F, Fornace AJ. UV Irradiation stimulates levels of p53 cellular tumor antigen in nontransformed mouse cells. Mol Cell Biol. 1993;13(7):4242-50.

27. Dulic V, Kaufmann WK, Wilson SJ et al. p53-dependent inhibition of cyclin-dependent kinase activities in human fibroblasts during radiation-induced G1 arrest. Cell. 1994;76(6):1013-23.

28. el-Deiry WS. Regulation of p53 downstream genes. Semin Cancer Biol. 1998;8(5):345-57.

29. Gottlieb TM. Oren, M. p53 and apoptosis. Sem Cancer Biol. 1998; 8:359-368.
30. Nigro JM, Baker SJ, Preisinger AC et al. Mutations in the p53 gene occur in diverse human tumour types. Nature. 1989;342 (6250):705-8.

31. Sigal A, Rotter V. Oncogenic mutations of the p53 tumor suppressor: The Demons of the Guardian of the Genome. Cancer Res. 2000;1560:6788-6793.

32. Hollstein M, Sidransky D, Vogelstein B et al. p53 mutations in human cancers. Science. 1991;253(5015):49-53.

33. Caron de Fromentel C, Soussi T. TP53 tumor suppressor gene: a model for investigating human mutagenesis. Genes Chromosomes Cancer 1992;4(1):1-15.

34. Lowe SW, Ruley HE, Jacks T et al. p53-dependent apoptosis modulates the cytotoxicity of anticancer agents. Cell. 1993;74 (6):957-67.

35. Fan S, Smith ML, Rivet DJ et al. Disruption of p53 function sensitizes breast cancer MCF-7 cells to cisplatinum and pentoxifylline. Cancer Res. 1995;55:1649-54.

36. Brachman DG, Beckett M, Graves D et al. p53 mutation does not correlate with radiosensitivity in 24 head and neck cancer cells lines. Cancer Res. 1993;53:3667-9.

37. van Oijen MG, Slootweg PJ. Gain-of-function mutations in the tumor suppressor gene p53. Clin Cancer Res. 2000;6(6):2138-45.

38. Ory K, Legros Y, Auguin C et al. Analysis of the most representative tumour-derived p53 mutants reveals that changes in protein conformation are not correlated with loss of transactivation or inhibition of cell proliferation. EMBO J. 1994;13(15):3496-504.

39. Blandino G, Levine AJ, Oren M. Mutant p53 gain of function: differential effects of different p53 mutants on resistance of cultured cells to chemotherapy. Oncogene. 1999;18(2):477-85.

40. Mosmann T. Rapid colorimetric assay for cellular growth and survival: application to proliferation and cytotoxicity assays. J Immunol Methods. 1983;65(1-2):55-63.

41. Blum KA, Lozanski G, Byrd JC. Adult Burkitt leukemia and lymphoma. Blood. 2004;104(10):3009-20.

42. Tulpule A. Multidrug resistance in AIDS-related lymphoma. Curr Opin Oncol. 2005;17:466-8.

43. Martin AC, Facchiano AM, Cuff AL et al. Integrating mutation data and structural analysis of the TP53 tumor-suppressor protein. Hum Mutat 2002;19(2):149-64.

44. Gutierrez MI, Cherney B, Hussain A et al. Bax is frequently compromised in Burkitt's lymphomas with irreversible resistance to Fas-induced apoptosis. Cancer Res. 1999;59(3):696-703.

45. Doucet JP, Hussain A, Al-Rasheed M et al. Differences in the expression of apoptotic proteins in Burkitt's lymphoma cell lines: potential models for screening apoptosis-inducing agents. Leuk Lymphoma. 2004;45(2):357-62.

46. Meijerink JP, Mensink EJ, Wang K et al. Hematopoietic malignancies demonstrate loss-of-function mutations of BAX. Blood. 1998;91 (8):2991-7.

Avaliação: Editor e dois revisores externos

Conflito de interesse: sem conflito de interesses

Recebido: Recebido 02/10/06

Aceito após modificações: 10/02/07 